\title{
Macrophage migration inhibitory factor produced by the tumour stroma but not by tumour cells regulates angiogenesis in the Bl6-FlO melanoma model
}

\author{
E Girard', C Strathdee', E Trueblood ${ }^{2}$ and C Quéva*,I \\ 'Hematology Oncology Research Area, Amgen Inc., Seattle, WA, USA; ${ }^{2}$ Pathology, Comparative Biology Safety Sciences, Amgen Inc., Seattle, WA, USA
}

BACKGROUND: Macrophage migration inhibitory factor (MIF) has been proposed as a link between inflammation and tumorigenesis. Despite its potentially broad influence in tumour biology and prevalent expression, the value of MIF as a therapeutic target in cancer remains unclear. We sought to validate MIF in tumour models by achieving a complete inhibition of its expression in tumour cells and in the tumour stroma.

METHODS: We used MIF shRNA-transduced BI6-FIO melanoma cells implanted in wild-type and MIF-/ - C57BI6 mice to investigate the effect of loss of MIF on tumour growth. Cytokine detection and immunohistochemistry (IHC) were used to evaluate tumours ex vivo.

RESULTS: Macrophage migration inhibitory factor shRNA inhibited expression of MIF protein by BI6-FI0 melanoma cells in vitro and in vivo. In vitro, the loss of MIF in this cell line resulted in a decreased response to hypoxia as indicated by reduced expression of VEGF. In vivo the growth of BI6-FIO tumours was inhibited by an average of $47 \%$ in the MIF - / - mice compared with wild-type but was unaffected by loss of MIF expression by the tumour cells. Immunohistochemistry analysis revealed that microvessel density was decreased in tumours implanted in the MIF - / - mice. Profiling of serum cytokines showed a decrease in pro-angiogenic cytokines in MIF - / - mice.

CONCLUSION: We report that the absence of MIF in the host resulted in slower tumour growth, which was associated with reduced vascularity. While the major contribution of MIF appeared to be in the regulation of angiogenesis, tumour cell-derived MIF played a negligible role in this process.

British Journal of Cancer (2012) I 07, |498-1505. doi:I0.1038/bjc.2012.392 www.bjcancer.com

Published online 6 September 2012

(C) 2012 Cancer Research UK

Keywords: macrophage migration inhibitory factor; MIF; angiogenesis; melanoma

Macrophage migration inhibitory factor (MIF) is a multifunctional cytokine, with complex and wide reaching activities, which has been proposed as a bridge between inflammation and tumorigenesis (Bucala and Donnelly, 2007). Macrophage migration inhibitory factor has been implicated in many aspects of tumour cell biology. Macrophage migration inhibitory factor was shown to control autonomous properties of tumour cells, such as the regulation of proliferation, apoptosis, DNA-damage response, senescence and invasion (Petrenko and Moll, 2005; Welford et al, 2006; Bucala and Donnelly, 2007; Fingerle-Rowson and Petrenko, 2007; Lue et al, 2007; Nemajerova et al, 2007b; Bifulco et al, 2008; Verjans et al, 2009; Dessein et al, 2010). Macrophage migration inhibitory factor also acts within the tumour stoma to promote angiogenesis and immune escape (Abe et al, 2001; Krockenberger et al, 2008; Zhou et al, 2008; Rendon et al, 2009; Mittelbronn et al, 2011). In addition, a high level of circulating MIF in serum has been reported in many cancer settings highlighting its potential as a detection biomarker (Grieb et al, 2010).

Most cells of the immune system as well as endothelial, endocrine, and epithelial cells produce MIF (Calandra and

*Correspondence: Dr C Quéva; E-mail: cmqueva@gmail.com Received I March 2012; revised 18 June 2012; accepted 3 August 2012; published online 6 September 2012
Roger, 2003). Macrophage migration inhibitory factor is predominantly localised in the cytoplasm and released by a non-conventional secretion pathway (Merk et al, 2009). Upon release, MIF triggers a number of signalling pathways utilising membrane-associated and intracellular binding partners. Macrophage migration inhibitory factor binds its best-characterised extracellular receptor CD74 in a complex with CD44. This binding triggers the sustained activation of the MAPK pathway, delivering a proliferative signal and the activation of Akt leading to inhibition of apoptosis (Leng et al, 2003; Meyer-Siegler et al, 2004; Lue et al, 2006, 2007, 2011; Shi et al, 2006; Li et al, 2009). The CXCR2 and CXCR4 chemokine receptors also bind to MIF, an interaction that may contribute to the recruitment of inflammatory cells (Bernhagen et al, 2007; Schwartz et al, 2009). Through physical interaction and inhibition of the cytosolic Jab1/CSN5 subunit of the COP9 signalosome, MIF inhibits AP-1 activity and the ubiquitin-mediated degradation of a number of proteins that play important roles in cell-cycle control and DNA-damage checkpoints (Kleemann et al, 2000; Nemajerova et al, 2007a, b). Jab1/CSN5dependent stabilisation of HIF- $1 \alpha$ is enhanced by MIF, leading to the subsequent activation of hypoxia-responsive genes (Bozza et al, 1999; Honma et al, 2000; Gregory et al, 2006; Winner et al, 2007; Rendon et al, 2009). Functional screens and the use of fibroblasts and macrophages derived from MIF $-/-$ mice have 
unravelled a role for MIF as an antagonist of p53 tumour suppressor protein (Hudson et al, 1999; Mitchell et al, 2002; Fingerle-Rowson et al, 2003). Macrophage migration inhibitory factor deletion resulted in premature growth arrest, resistance to $\mathrm{H}-\mathrm{Ras}^{\mathrm{v} 12}$-induced transformation and to p53-dependent apoptosis.

Despite the tantalizing rationale linking MIF and tumour development, the value of inhibiting MIF has not been convincingly validated in preclinical models of cancer in vivo. Although neuroblastoma SK-N-DZ cells stably transfected with MIF antisense vector failed to grow in mice, other studies targeting MIF have shown only a modest effect on tumour growth (Ren et al, 2006). Inhibition of tumour growth by $\leqslant 40 \%$ was observed after treatment of Colon 26 or $38 \mathrm{C} 13$ syngeneic tumour models with MIF-neutralising antibodies (Chesney et al, 1999; Ogawa et al, 2000). Similarly treatment with ISO-1, a small molecule inhibitor of MIF activity led to $40 \%$ tumour growth inhibition in the DU-145 prostate tumour model (Meyer-Siegler et al, 2006).

We reasoned that the modest activity generated by MIF inhibitors in vivo might be the result of incomplete inhibition of MIF. Indeed, antibody treatment may not neutralise MIFdependent activities in the cytoplasm. To the same extent, ISO-1 dosing regimen may not lead to a complete and sustained inhibition of MIF. In order to resolve this question, we used a combination of shRNA targeting MIF in tumour cells and implantation of these tumour cells in wild-type and MIF - / mice. In a B16-F10 melanoma model, we found that MIF produced by tumour cells is dispensable and that most of the tumourpromoting activity is provided by host-derived MIF, through the stimulation of angiogenesis. We also report on the effect of systemic MIF inactivation in the tumour stroma in additional in vivo models derived from mouse and human cell lines.

\section{MATERIALS AND METHODS}

\section{Cell culture and reagents}

Mouse cell lines B16-F10, CT26, 4T1, and Lewis Lung (LL/2) as well as human cell lines Raji, HT29, and HCT116 were obtained from American Type Culture Collection (ATCC, Manassas, VA, USA). Cells were routinely cultured in Dulbecco's Modified Eagle Medium (DMEM) containing 10\% fetal bovine serum (Hyclone, Logan, UT, USA), penicillin with streptomycin and L-Glutamine (Invitrogen, Grand Island, NY, USA). Cultures were grown at $37^{\circ} \mathrm{C}$ in $5 \% \mathrm{CO}_{2}$.

\section{Generation of MIF shRNA B16-F10}

The lentiviral vector backbone has been described by Lippa et al (2007) and was modified for improved expression in murine cell types by incorporating a T-Rex tetracycline repressor gene (Invitrogen) expressed from the strong MSCVLTR promoter, as well as a puromycin-resistance gene expressed from the human PGK promoter and bovine growth hormone polyadenylation signal (Invivogen, Grand Island, NY, USA) (Lippa et al, 2007). The shRNA expression components were incorporated in a doublecopy format as a Gateway cassette in the SIN-LTR of the vector backbone, such that two expressed copies were generated following incorporation into the genome of the target cell. Gene-specific shRNA triggers were designed and cloned into the pENTR/hH1/TO T-Rex expression vector according to the manufacturer's protocols (Invitrogen). The sense-strand sequence of each shRNA trigger was as follows: shMIF-361, $5^{\prime}$-CCGGGTCTACATCAACTATTACGA-3'; shCTRL, 5'-GTCTCCACGCGCAGTACATTA-3' . Lentiviral vector stocks were generated according to the manufacturer's protocols (Invitrogen). B16-F10 cells were transduced with specific lentiviral vectors by incubating $10^{6}$ cells with $10^{7} \mathrm{TU}$ of vector in a single well of a 12-well tissue culture dish in $500 \mu$ l of RPMI containing $10 \mu \mathrm{g} \mathrm{ml}^{-1}$ DEAE Dextran for $6 \mathrm{~h}$. Two days after transduction, cells were selected in media containing $2.5 \mu \mathrm{g} \mathrm{ml}^{-1}$ puromycin (Invivogen). To test induction of the shRNA, cells were cultured in standard DMEM with the addition of $1 \mu \mathrm{g} \mathrm{ml}^{-1}$ doxycycline for $24 \mathrm{~h}$.

\section{Tumour growth in wild-type and MIF $-I-$ mice}

Tumour cell lines were implanted subcutaneously in the right flank of wild-type and MIF-I- mice in $100 \mu$ l of Matrigel (BD, San Jose, CA, USA) diluted 1:1 with PBS. The optimal density of tumour cells to implant was determined experimentally in wildtype mice. The following amounts of tumour cells were implanted: $5 \times 10^{5}$ B16-F10, CT26, $4 \mathrm{~T} 1$, or LL/2 cells, $1 \times 10^{6}$ HT29 cells, or $5 \times 10^{6}$ HCT116 or Raji cells. MIF $-/-$ mice were generated by Honma et al (2000) and bred for $>10$ generations to C57Bl/6 or $\mathrm{Balb} / \mathrm{c}$ mice. Balb/c MIF - / - mice were also intercrossed to CB17-Prkdcscid to generate the MIF mutation in an immunedeficient background to allow for implantation of human tumour cell lines. Colonies of wild-type and MIF - I- mice were bred at Charles River (Wilmington, MA, USA). The mice used in each experiment were a mix of males and females ranging in age from 6 to 10 weeks. An equal distribution of age and sex was targeted for each experimental group. When tumours transduced with control or MIF shRNA were implanted into wild-type or MIF - / - mice, subjects were distributed into groups for doxyxyline treatment when the average tumour volume reached $100 \mathrm{~mm}^{3}$. Doxycycline was administered $\left(2 \mathrm{mg} \mathrm{ml}^{-1}\right.$ with $5 \%$ sucrose in drinking water ad libidum) until the termination of the study. Tumour volumes were measured with a digital caliper and body weights were recorded three times per week. Tumour volumes were approximated using the formula(width ${ }^{2} \times$ length)/2. All continuous measurements were expressed as mean \pm s.e. Statistical analysis consisted of RM-ANOVA on log-transformed volume with Dunnett's test for significance. All experimental procedures were approved by the Institutional Animal Care and Use Committee and in accordance with the standards of the Association for Assessment and Accreditation of Laboratory Animal Care.

\section{Western blotting analysis}

For western blot analysis cells were lysed directly on the tissue culture plate in RIPA buffer with protease and phosphatase inhibitors (Sigma, St. Louis, MO, USA) for $30 \mathrm{~min}$ at $4{ }^{\circ} \mathrm{C}$. Lysates were quantified by Bradford analysis (Thermo Scientific, Rockville, $\mathrm{MD}$, USA). In all, $40 \mu \mathrm{g}$ of total protein was subjected to electrophoresis on Novex 4-20\% Tris-Glycine Gels (Invitrogen), and blotted to PVDF membranes. Antibodies used against mouse target proteins were MIF (Abcam ab7207, 1:1000, Cambridge, MA, USA), VEGF (Santa Cruz Biotechnology sc507, Santa Cruz, CA, USA, $1: 100$ ), and $\beta$-actin (Sigma A2066, 1:500).

\section{Quantitative reverse transcription PCR}

RNA was extracted from frozen B16-F10 cells using Qiagen miniprep RNA extraction kit as directed (Qiagen RNeasy mini, Valencia, CA, USA). First-strand cDNA synthesis was performed using the Invitrogen SuperScript III First-Strand Synthesis System for RT-PCR using Oligo(dT) primers. Quantitative PCR was conducted in a 384-well format using Taqman Master Mix (Invitrogen) under standard conditions with probes against mouse MIF (Invitrogen \#Mm01611157_gH) and GAPDH (Invitrogen \#4352339E).

\section{Immunohistochemistry}

Tumour samples were harvested on day 13 after implantation and at the time of study termination on day 20. Tumour samples were fixed in formalin, embedded in paraffin and $4 \mathrm{~mm}$ histologic 
sections were prepared. Sections were de-paraffinized and subjected to aDecloaker Pressure Instrument (Biocare, Concord, CA, USA) for antigen retrieval. Each tumour was probed for CD31 (BD Bioscience \#553370, $1 \mu \mathrm{g} \mathrm{ml}^{-1}$ ), phospho-histone $\mathrm{H} 3$ (Millipore, Billerica, MA, USA/Upstate \#06-570, $1 \mu \mathrm{g} \mathrm{ml}^{-1}$ ), cleaved caspase-3 (Cell Signaling Technology, Danvers, MA, USA; \#9661) and F4/80 (Abcam, \#ab6640, $2 \mu \mathrm{g} \mathrm{ml}^{-1}$ ). Briefly, each slide was blocked for $15 \mathrm{~min}$ with $3 \%$ Peroxidase Block and an additional 10 min with Protein Block (Dako, Carpinteria, CA, USA). The primary antibodies were incubated for $60 \mathrm{~min}$ followed by incubation with the secondary Mach3 Rabbit Probeand Mach3 Rabbit Alkaline Phosphatase (Biocare). Finally, slides were treated with Perm Red (Dako) for $10 \mathrm{~min}$ and Hematoxylin (Dako) for $1 \mathrm{~min}$. A xylene-based mountant was used.

For morphometric analysis digital images of three representative $\times 10$ microscopic fields were taken using a QImaging Micropublisher 5.0 digital camera attached to a Nikon E600 microscope. Fields were selected to avoid areas of necrosis; however, the photographer was blinded to the mouse genotype and tumour group. MetaVue version 6.2r6 (Universal Imaging Corp., Downingtown, PA, USA) imaging software was used to establish a threshold on the red chromogen labelling the CD31-positive endothelial cells lining vessel walls and to calculate the area thresholded. The result for each image was expressed as vessel area in $\mu \mathrm{m}^{2}$ per $\mathrm{mm}^{2}$ of tumour and the average of the three images provided the value for each tumour. An unpaired Student's $t$-test was used to compare the mean vessel area.

\section{Cytokine analysis}

Serum samples were harvested for mouse cytokine/chemokine analysis on day 13 and at termination of the study on day 20. The Linco pre-mixed cytokine/chemokine 22 multiplex kit (Millipore) was used as directed for cytokine profiling on a luminex instrument (Millipore). Mouse VEGF was analysed by ELISA (R\&D Systems, Minneapolis, MN, USA). An unpaired Student's $t$-test was used to compare group means.

\section{RESULTS}

\section{shRNA knockdown of MIF expression}

To test the influence of MIF produced by tumour cells on tumour growth in vitro and in vivo, we transduced the B16-F10 mouse melanoma cell line with a lentivirus expressing either control or MIF targeting shRNA. B16-F10 cells express MIF mRNA and protein; treatment with doxycycline did not change the level of expression in cells transduced with the control shRNA (Figure 1A and B). In the absence of doxycycline, a $75 \%$ decrease in MIF mRNA compared with control B16-F10 was observed by quantitative RT-PCR, indicating that our vector enabled the transcription of MIF shRNA in basal condition (Figure 1A). In presence of doxycycline, MIF shRNA elicited a 90\% decrease in MIF mRNA expression. Macrophage migration inhibitory factor protein was barely detectable by western blot in the absence of doxycycline and not detectable after the addition of doxycycline to the MIF shRNAtransduced cells compared with control (Figure 1B). Based on these results, MIF expression appeared to be constitutively knocked down by MIF shRNA at both the mRNA and protein level. In agreement with this observation, we did not observe any phenotypic differences in vitro or in vivo as a consequence of doxycycline treatment (data not shown and Figure 3B).

\section{In vitro characterisation of MIF-deficient B16-F10 melanoma cells}

We characterised the effect of inhibiting MIF expression on B16-F10 cell viability and proliferation. A kinetic analysis revealed

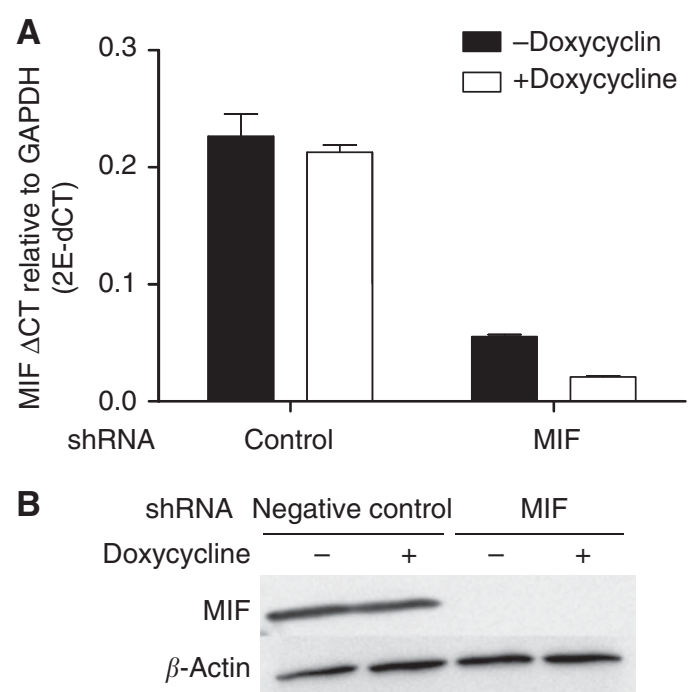

Figure I Inhibition of MIF mRNA and protein expression in BI6-FIO mouse melanoma cells transduced a lentiviral construct expressing MIFtargeting shRNA. Pools of BI6-FIO expressing a control or MIF shRNA were grown under standard conditions with or without $2.5 \mu \mathrm{gm} l^{-1}$ doxycyclin for $48 \mathrm{~h}$. (A) RNA was isolated and cDNA was synthesised. Primers against MIF and GAPDH (control) were used in quantitative PCR. Data are shown as $\Delta C_{t}$ for each condition between MIF and GAPDH. (B) Protein was harvested from cell lysates and western blot was performed on $40 \mu \mathrm{g}$ total protein. Blots were probed with an anti-MIF rabbit polyclonal antibody and an anti- $\beta$ actin antibody.

a faster rate of proliferation upon MIF inhibition (Supplementary Figure S1A and B). The increased proliferation was accompanied by a higher level of cyclin D1, phosphorylated retinoblastoma protein and phosphorylated p42/44 MAPK (Supplementary Figure S1C). The cause for this phenotype was not further investigated as we did not find any consequence of MIF inhibition on cell proliferation as assessed by phospho-histone $\mathrm{H} 3$ staining in vivo (Supplementary Figure S2A).

We also characterised the consequence of reducing MIF expression in B16-F10 cells in vitro in response to hypoxia, where MIF was proposed to play a role. Macrophage migration inhibitory factor was reported to be upregulated by hypoxia, to be necessary for the full activity of HIF- $1 \alpha$, and to be required for the full induction of hypoxia-inducible genes such as VEGF (Winner et al, 2007). We therefore investigated VEGF expression in B16-F10 cells. Under normoxic conditions expression of both MIF and VEGF was inhibited by MIF-targeted shRNA (Figure 2A). In support of a role for MIF in response to hypoxia, expression of secreted VEGF protein was lower in MIF shRNA-transduced B16-F10 cells than in control cells under both normoxic and hypoxic $\left(\begin{array}{lll}0.5 \% & \mathrm{O}_{2}\end{array}\right)$ conditions (Figure 2B). In normoxic growth conditions VEGF secretion by MIF shRNA-transduced cells was $63 \%$ lower than in control cells. After $24 \mathrm{~h}$ of hypoxic treatment VEGF secretion was $50 \%$ lower in MIF shRNA transduced than in control B16-F10 cells (Figure 2B).

\section{Growth inhibition of B16-F10 syngeneic tumours by loss of host-derived MIF}

To test the role of MIF on tumour growth in vivo, pools of B16-F10 cells selected to express a nonsense control shRNA or anti-MIF shRNA were implanted subcutaneously in syngeneic C57BL/6 mice. In addition, we tested the role of MIF produced by the host by implanting the same cell pools in MIF - I- mice (Honma et al, 2000 ). Figure $3 \mathrm{~A}$ is an example of three in vivo studies. A $47 \%$ reduction in tumour growth was observed when comparing tumours grown in wild-type $v s \mathrm{MIF}-1-$ mice. This difference 
was statistically significant $(P<0.05)$. The average tumour growth inhibition of the three studies was $43 \% \pm 7$. In contrast, the loss of MIF expression in the B16-F10 melanoma cell line did not affect tumour growth. This result was not altered by the addition of doxycycline in the drinking water, indicating that the lack of effect is not due to regaining MIF expression in vivo in the absence of doxycycline (Figure 3A). The knockdown of MIF expression was

A
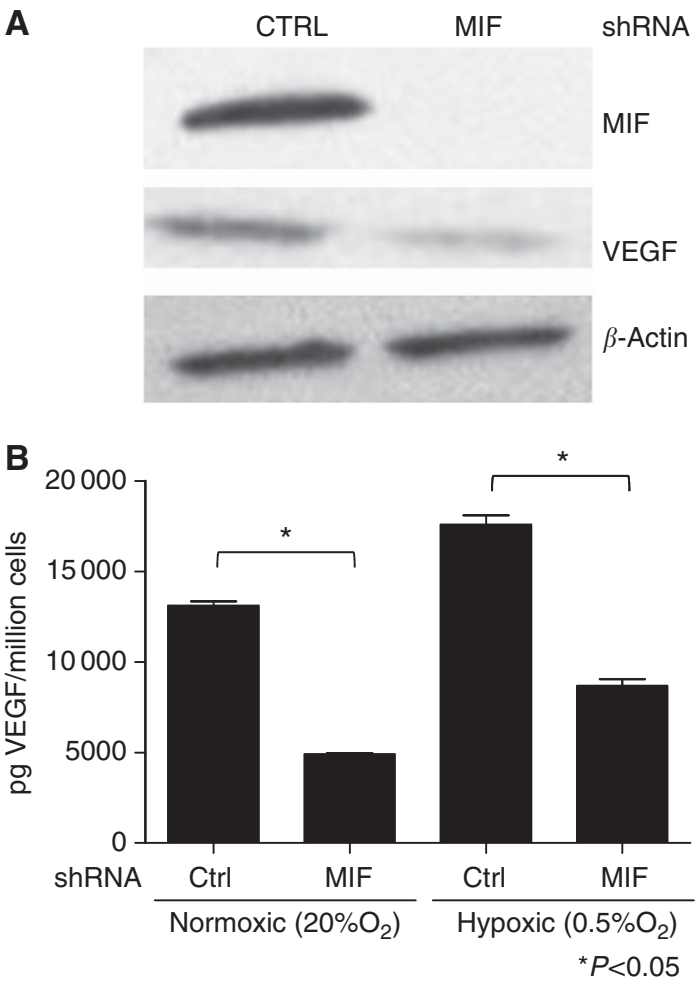

Figure 2 MIF-regulated VEGF expression in vitro. (A) B I 6-FIO cells were grown $48 \mathrm{~h}$ in a normoxic $\left(20 \% \mathrm{O}_{2}\right)$ environment with or without Doxycyclin. Protein was harvested from cell lysates and western blot was performed on $40 \mu \mathrm{g}$ total protein. Blots were probed with antibodies against MIF, VEGF, or $\beta$-actin. (B) BI6-FIO cells transfected with shRNA were grown $24 \mathrm{~h}$ in normoxic conditions after which plates were grown an additional $24 \mathrm{~h}$ under normoxic or hypoxic $\left(0.5 \% \mathrm{O}_{2}\right)$ conditions. Cell supernatant was collected and VEGF secretion was evaluated by ELISA. $(* P<0.05)$. confirmed by quantitative RT-PCR (Figure 3B) and ELISA (Figure 3C) in tumour lysates at termination of the study. Both quantitative RT-PCR and ELISA showed that the major contribution of total MIF in the control B16-F10 tumours originated from the tumour cells and not from the host (Figure 3B and C).

\section{Reduction of angiogenesis in B16-F10 tumours growing in MIF - / - mice}

To explore the mechanism of tumour growth inhibition in MIF - / - mice immunohistochemistry (IHC) analysis of tumours was used to evaluate tumour cell proliferation, apoptosis, vascularisation and the presence of tumour-associated macrophages. Two time points were compared, an intermediate time point at day 13 after tumour implant and the terminal time point at day 20. Tumour samples were collected at both time points to ensure that we were capturing early events leading to tumour growth inhibition. Cell proliferation (as measured by phospho Histone H3 staining) and apoptosis (as assessed by cleaved Caspase-3 staining) showed no significant difference between tumours grown in wild-type and MIF - / - mice (Supplementary Figure S2A and data not shown). In contrast, we consistently observed a decrease in the vessel area as assessed by CD31 staining in tumours growing in the MIF - I- mice compared with wildtype mice (Figure 4A and B). A 40\% decrease in CD31 staining $(P<0.05)$ was evident at the two time points in the analysis (Figure 4B). The number of F4/80 stained cells were highly variable across tumours. We could not detect a significant difference between groups, although there was a trend $(P=0.09$ at day 20) toward an increased number of macrophages in tumours of MIF - / - mice (Supplementary Figure S2B).

\section{Cytokine analysis}

To further define the cause of the decrease in vascular density in B16-F10 tumours in MIF - / - mice, we investigated the level of VEGF in serum and in the B16-F10 tumour lysates. Despite the decrease in VEGF mediated by MIF shRNA in vitro in B16-F10 compared with control shRNA, no statistically significant differences could be observed at the day 13 or day 20 time points in vivo (Figure 5A). The lack of significant change in circulating and local tumour VEGF in vivo suggested that altered expression of this particular factor was not the reason for the observed reduction in vascularity.

The expression level of additional cytokines and chemokines potentially involved in MIF-mediated effects was then evaluated. In serum, four cytokines showed a statistically significant
A

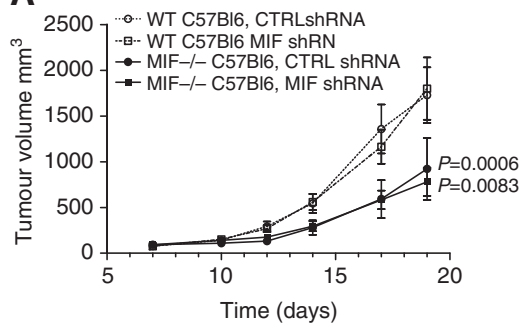

B

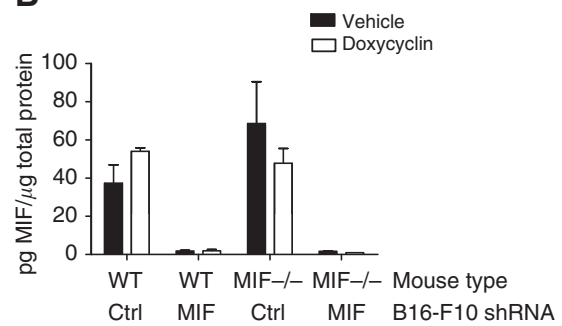

C

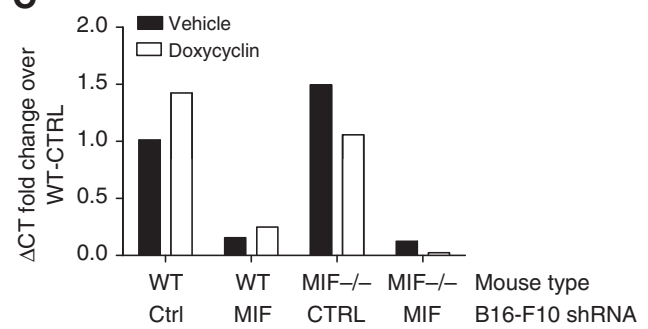

Figure 3 Growth inhibition of BI6-FIO subcutaneous syngeneic tumours in MIF- / - C57BI6 mice. (A) In all, I $\times 10^{5}$ BI6-FIO cells transduced with control or MIF shRNA in 50\% matrigel matrix solution were implanted subcutaneously in the right flank of age-matched wild-type C57BI/6 or MIF - / C57BI/6 congenic strain. After 7 days of tumour growth, mice were randomized by tumour size into treatment groups of either standard drinking water or water with $2 \mathrm{mg} \mathrm{ml}^{-1}$ doxycyclin with 5\% sucrose. Groups not treated with doxycyclin are not shown. Tumours were measured with digital calipers three times per week for 2 weeks. (B) Protein lysates were made from tumours harvested at the termination of the study. Lysates were evaluated for MIF expression by ELISA. (C) A portion of each tumour harvested at the termination of the study was preserved in RNALater. RNA was isolated and cDNA was synthesised. Primers against MIF, VEGF, and GAPDH were used in quantitative PCR. Data are shown as $\Delta \mathrm{C}_{t}$ comparing the control tumours from wild-type mice to MIF shRNA tumours from wild-type mice and control or MIF shRNA tumours from MIF - I - mice. 

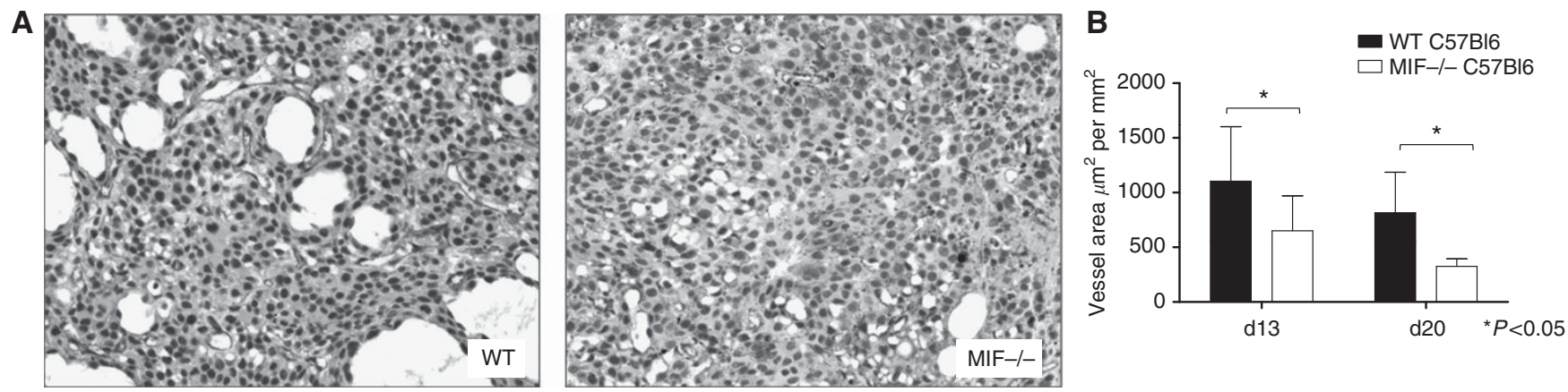

Figure 4 Reduced vascular density of BI6-FIO tumours growing in MIF - / - mice. (A) BI6-FIO tumour grown in wild-type or MIF - / - mice were collected at termination of the in vivo study and preserved in formalin. The proportion of endothelial cells present in the tumour was evaluated by $I \mathrm{HC}$ staining of CD31. Positive staining is visualised as red chromogen. Note the brown colour is melanin pigment inherent in the tumour and phagocytised (SP) by tumour-associated macrophages (melanophages). This pigment tended to be more prominent in the tumours of MIF KO mice. (B) Quantitated vessel area of BI6-FIO control tumours in wild-type and MIF - / - mice at the intermediate time point (day I3) and terminal time point (day 20). The area of CD3I positivity (vessel area) is expressed in microns per $\mathrm{mm}^{2}$ of tumour area $(* P<0.05)$.
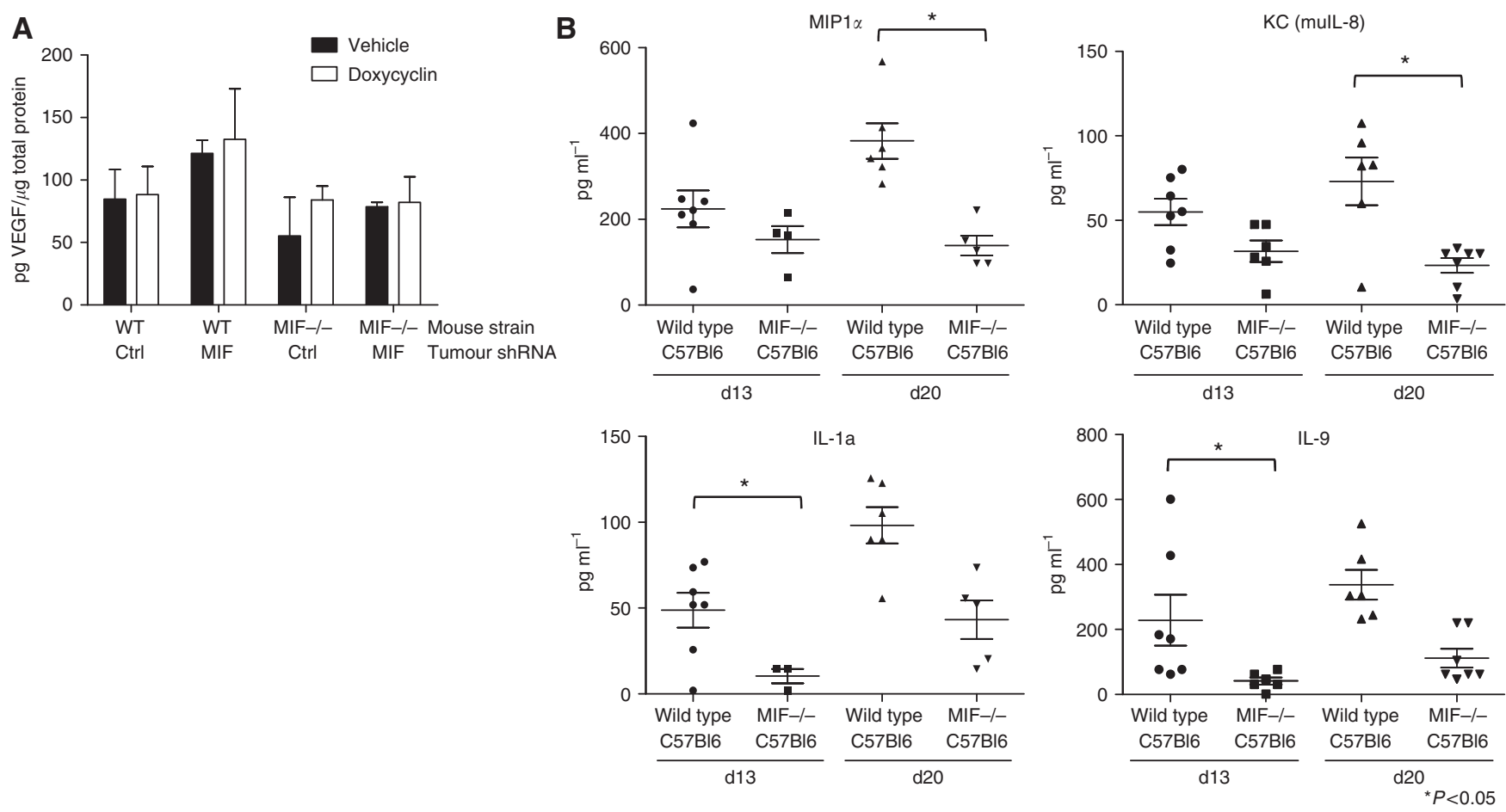

Figure 5 Expression of serum cytokines. (A) Serum was collected from all mice at termination of the study. Expression of VEGF in $50 \mu$ l undiluted mouse serum was evaluated by ELISA. (B) Serum collected at the intermediate and terminal time points was evaluated undiluted by Cytokine/chemokine luminex bead assay. The circulating levels of 4 of the 22 cytokines evaluated MIP-I $\alpha, K C, I L-I \alpha$, and IL-9 were found to be reduced in the serum of MIF - I - mice compared with wild-type mice bearing BI6-FIO tumours $(* P<0.05)$.

differential expression level based on the MIF status of the mouse. At day 13, IL- $1 \alpha$ and IL-9 were decreased in tumour bearing MIF - I - mice compared with wild-type mice; the same trend was perpetuated at day 20 (Figure 5B). At day 13 and 20, MIP1 $\alpha$ (CCL3) and $\mathrm{KC}$ (CXCL1) were significantly reduced in the serum from MIF $-/$ - mice, the difference being only significant $(P<0.05)$ at day 20. MCP-1 (CCL2) showed a consistent trend at days 13 and 20 for a lower expression level in MIF - / - bearing B16-F10 tumours (data not shown). These differences were only observable in the circulation, but not in tumour lysates. G-CSF, GM-CSF, IFN $\gamma$, IP10, IL-2, IL-4, IL-5, IL-6, IL-7, IL-10, IL-12, IL-13, IL-15, IL-17, and RANTES while within the detection limits of the assay did not show any significant difference in expression between wild-type and MIF - / - mice or tumours (data not shown). The modulation of cytokine levels appeared to be elicited by the host response to the B16-F10 tumour as we were not able to detect any significant difference in any cytokine between non-tumour bearing wild-type and MIF $-I-$ mice (data not shown).

\section{Growth of additional tumour models in MIF $-/-$ mice}

To evaluate the broader relevance of MIF inhibition, additional tumour cell lines of mouse origin (LL/2, 4T1, CT26) or of human origin (HT-29, HCT116, Raji) were introduced in wild-type and MIF - / - mice in a suitable syngeneic or SCID genetic background. Macrophage migration inhibitory factor shRNA were 
tested in B16-F10 (see above) and in HT-29 (data not shown). Given that we did not detect any change in growth rate between control and MIF shRNA-transduced tumour cells in vitro and in vivo, the effect of MIF shRNA was not evaluated in the other tumour models. No anti-tumour efficacy was observed in any of the models, with the exception of the Raji tumour model that showed a trend for a reduced growth rate in the MIF $-I-$ mice (Supplementary Figure S3). A significant decrease $(30 \%, P=0.015)$ in blood vessel density, as assessed by CD31, and in proliferation $(28 \% P=0.05)$ by $\mathrm{pH} 3$ staining was observed in Raji Xenografts in MIF - / - mice. Histological analysis of CD31 staining in the LL/2 model did not reveal any significant inhibition of angiogenesis (data not shown). The other models were not assessed by IHC. Cytokine evaluation of the CT26 and 4T1 tumour bearing mice did not reveal any significant changes in circulating cytokine profile, in contrast to our observation in the B16-F10 studies (data not shown).

\section{DISCUSSION}

Despite its broad potential influence, the importance of MIF as a therapeutic target in cancer remains to be established (Bucala and Donnelly, 2007; Rendon et al, 2009). Pharmacological inhibition of MIF activity, using antibodies that neutralises MIF binding to CD74, or small molecules such as ISO-1 than inhibit MIF tautomerase activity and binding to $\mathrm{CD} 74$ have not yielded profound activity in preclinical models in vivo (Chesney et al, 1999; Ogawa et al, 2000; Meyer-Siegler et al, 2006; Leng et al, 2011). These two therapeutic approaches have a limitation: antibodies may not be able to inhibit intracellular MIF function mediated by its interaction with Jab1/CSN5 and one can speculate that ISO-1 dosed twice a week may not lead to sustained inhibition of MIF function (Kleemann et al, 2000; Lue et al, 2006, 2007; Meyer-Siegler et al, 2006; Nemajerova et al, 2007a, b). In our experience, despite achieving a near complete removal of MIF from both the B16-F10 tumour cells and the host mouse, we inhibited tumour growth by $43 \%$. This result failed to improve upon the reported $40 \%$ inhibition achieved with neutralising MIF antibodies or ISO-1 (Chesney et al, 1999; Ogawa et al, 2000; Meyer-Siegler et al, 2006). Targeting MIF expression in B16-F10 mouse melanoma cells had no measurable consequence on tumour growth in vivo. By contrast, the absence of MIF in the host stroma fully accounted for the reduced tumour growth rate observed in the MIF - Imice. The most likely cause for this reduced tumour growth was a decrease in tumour angiogenesis.

In the B16-F10 melanoma cell line MIF was induced by hypoxia and in turn modulated the downstream response to hypoxia, as exemplified by the reduction in VEGF expression level elicited by MIF shRNA (Figure 2). In B16-F10 subcutaneous tumours however, we were not able to demonstrate a contribution of the inhibition of MIF to the overall production of VEGF (Figure 5A). The VEGF levels were not found to be different in B16-F10 tumours transduced with MIF or control shRNA whether these tumours were implanted in wild-type or MIF - I - mice. Despite the lack of significant changes in VEGF expression, the most profound effect of MIF deficiency was the modulation of angiogenesis in the B16-F10 and Raji models. A reduction of angiogenesis in MIF $-1-$ mice was also observed in the APC ${ }^{\mathrm{min} /+}$ mouse model of colorectal cancer (Wilson et al, 2005). In this model, as in our experience with the B16-F10, no alteration in tumour cell proliferation and apoptosis could be observed in vivo. However, our results differ from previously published results in which B16-F10 transfected with MIF siRNA exhibited a delayed onset of tumour growth in wild-type mice attributed to a reduction of blood vessel density and an increase in the expression of thrombospondin-1 (Culp et al, 2007). In our experiment, thrombospondin-1 protein was not detectable by western blot in
B16-F10 tumours (data not shown). The identity of the MIF producing cells in the tumour stroma is not clear, although MIF is known to be produced at a high level by many cell types including macrophages, neutrophils and endothelial cells (Calandra and Roger, 2003). Four cytokines were consistently found to be expressed at reduced level in the serum of MIF $-/$ - growing B16-F10 tumours. While we cannot exclude the possibility of a relationship between the smaller tumour size and the reduced cytokine level in the MIF-/- mice, the observation that, particularly for KC and MIP- $1 \alpha$, the level found in serum of MIF - / - at day 20 (average tumour volume $800 \mathrm{~mm}^{3}$ ) does not rise above the level of the wild-type mice at day 13 (average tumour volume $500 \mathrm{~mm}^{3}$ ) makes this possibility less likely. Among the cytokines that we found decreased in the serum of MIF - Imice, KC (a functional homologue of human IL-8), MIP-1 $\alpha$ and IL- $1 \alpha$ have been reported to directly or indirectly promote angiogenesis and to be regulated by MIF (White et al, 2001; Payne and Cornelius, 2002; Apte et al, 2006; Kudrin et al, 2006; Wu, 2008). These cytokines may account for the observed inhibition of vascularisation in the absence of any change in VEGF. Alternatively, MIF may also directly promote the proliferation of endothelial cells. Macrophage migration inhibitory factor-neutralising $\mathrm{mAbs}$ have been indeed shown to inhibit human endothelial cells proliferation in vitro (Chesney et al, 1999; Ogawa et al, 2000).

MIF involvement in the regulation of angiogenesis appears to be tumour specific. No defect in the vasculature in the MIF - /mice was reported (Bozza et al, 1999; Honma et al, 2000; Gregory et al, 2006). In addition, the decrease in serum cytokine expression between wild-type and MIF - / - mice was not observed in the absence of tumour or with tumours insensitive to MIF knockout. The assessment of the circulating level of these cytokines may offer a biomarker to evaluate the activity of potential MIF-targeting therapeutics.

\section{CONCLUSIONS}

Understanding the role of MIF in neoplastic development and progression is complicated by the pleiotropic influences that MIF plays in many tumorigenic processes. This study was conducted to understand the full contribution of MIF activities by combining its inactivation in tumour cells by shRNA and in the tumour stroma by using MIF - / - mice. Among the models we tested, we found the B16-F10 melanoma to be the most sensitive to loss of MIF activity. In vitro, the loss of MIF in this cell line resulted in a decreased response to hypoxia based upon reduced expression of VEGF. The latter however had little influence on the growth of B16-F10 in vivo. While the major contribution of MIF appears to be in the regulation of angiogenesis, the tumour cell-derived MIF played a negligible role in this process. We show that MIF produced by the host was a critical factor in the regulation of angiogenesis. We speculate that MIF regulation of tumour vascularisation occurs through its ability to regulate the expression of pro-angiogenic chemokines and the modulation of the recruitment and/or the activity of pro-inflammatory cells.

\section{ACKNOWLEDGEMENTS}

We thank Katsuji Sugie (La Jolla Institute for Allergy and Immunology) for running the mouse MIF elisa assay, John Scholler and Jesse Gurgel for helping with the generation of the MIF shRNA lentiviral vector, Rainy Regan and Derek Masse for help with the in vivo experiments, Larry Woody, Janine Harrison, and Linda Cherepow for help with histology, Winnie Weng for statistical analysis and Roy Black, Tony Polverino, and Lynn Bonham for critically reading the manuscript. 


\section{Conflict of interest}

All authors are or were Amgen Inc. employees and shareholders.

\section{Author contributions}

EG participated in the design of the studies, performed or supervised the experiment with the exception of the

\section{REFERENCES}

Abe R, Peng T, Sailors J, Bucala R, Metz CN (2001) Regulation of the CTL response by macrophage migration inhibitory factor. J Immunol 166: 747-753

Apte RN, Dotan S, Elkabets M, White MR, Reich E, Carmi Y, Song X, Dvozkin T, Krelin Y, Voronov E (2006) The involvement of IL-1 in tumorigenesis, tumor invasiveness, metastasis and tumor-host interactions. Cancer Metastasis Rev 25: 387-408

Bernhagen J, Krohn R, Lue H, Gregory JL, Zernecke A, Koenen RR, Dewor M, Georgiev I, Schober A, Leng L, Kooistra T, Fingerle-Rowson G, Ghezzi P, Kleemann R, McColl SR, Bucala R, Hickey MJ, Weber C (2007) MIF is a noncognate ligand of CXC chemokine receptors in inflammatory and atherogenic cell recruitment. Nat Med 13: 587-596

Bifulco C, McDaniel K, Leng L, Bucala R (2008) Tumor growth-promoting properties of macrophage migration inhibitory factor. Cur Pharm Des 14: 3790-3801

Bozza M, Satoskara R, Lin G, Lu B, Humbles A, Gerard C, David JR (1999) Targeted disruption of migration inhibitory factor gene reveals its critical role in sepsis. J Exp Med 189: 341-346

Bucala R, Donnelly SC (2007) Macrophage migration inhibitory factor: a probable link between inflammation and cancer. Immunity 26: 281-285

Calandra T, Roger T (2003) Macrophage migration inhibitory factor: a regulator of innate immunity. Nat Rev Immunol 3: 791-800

Chesney J, Metz C, Bacher M, Peng T, Meinhardt A, Bucala R (1999) An essential role for macrophage migration inhibitory factor (MIF) in angiogenesis and the growth of a murine lymphoma. Mol Med 5: 181-191

Culp WD, Tsagozis P, Burgio M, Russell P, Pisa P, Garland D (2007) Interference of macrophage migration inhibitory factor expression in a mouse melanoma inhibits tumor establishment by up-regulating thrombospondin-1. Mol Cancer Res 5: 1225-1231

Dessein A-F, Stechly L, Jonckheere N, Dumont P, Monté D, Leteurtre E, Truant S, Pruvot F-R, Figeac M, Hebbar M, Lecellier C-H, Lesuffleur T, Dessein R, Grard G, Dejonghe M-J, de Launoit Y, Furuichi Y, Prévost G, Porchet N, Gespach C, Huet G (2010) Autocrine induction of invasive and metastatic phenotypes by the MIF-CXCR4 axis in drug-resistant human colon cancer cells. Cancer Res 70: 4644-4654

Fingerle-Rowson G, Petrenko O (2007) MIF coordinates the cell cycle with DNA damage checkpoints. Lessons from knockout mouse models. Cell Div 222

Fingerle-Rowson G, Petrenko O, Metz CN, Forsthuber TG, Mitchell R, Huss R, Moll U, Müller W, Bucala R (2003) The p53-dependent effects of macrophage migration inhibitory factor revealed by gene targeting Proc Natl Acad Sci USA 100: 9354-9359

Gregory JL, Morand EF, McKeown SJ, Ralph J a, Hall P, Yang YH, McColl SR, Hickey MJ (2006) Macrophage migration inhibitory factor induces macrophage recruitment via CC chemokine ligand 2. J Immunol 177: 8072-8079

Grieb G, Merk M, Bernhagen J (2010) Macrophage migration inhibitory factor (MIF): a promising biomarker. Drug News Perspect 23: 257-264

Honma N, Koseki H, Akasaka T, Nakayama T, Taniguchi M, Serizawa I, Akahori H, Osawa M, Mikayama T (2000) Deficiency of the macrophage migration inhibitory factor gene has no significant effect on endotoxaemia. Immunology 100: 84-90

Hudson JD, Shoaibi M a, Maestro R, Carnero A, Hannon GJ, Beach DH (1999) A proinflammatory cytokine inhibits p53 tumor suppressor activity. J Exp Med 190: 1375-1382

Kleemann R, Hausser A, Geiger G, Mischke R, Burger-Kentischer A, Flieger O, Johannes FJ, Roger T, Calandra T, Kapurniotu A, Grell M, Finkelmeier D, Brunner H, Bernhagen J (2000) Intracellular action of the cytokine MIF to modulate AP-1 activity and the cell cycle through Jab1. Nature 408: $211-216$

Krockenberger M, Dombrowski Y, Weidler C, Ossadnik M, Hönig A, Häusler S, Voigt H, Becker JC, Leng L, Steinle A, Weller M, Bucala R, Dietl J, Wischhusen J (2008) Macrophage migration inhibitory factor immunohistochemical analysis, and contributed to writing this report. CS generated the lentiviral constructs and the transduced cell lines. ET performed the immunohistochemical analysis. CQ led the research and contributed to the study design and to the redaction of the manuscript.

Supplementary Information accompanies the paper on British Journal of Cancer website (http://www.nature.com/bjc) contributes to the immune escape of ovarian cancer by down-regulating NKG2D. J Immunol 180: 7338-7348

Kudrin A, Scott M, Martin S, Chung C-W, Donn R, McMaster A, Ellison S, Ray D, Ray K, Binks M (2006) Human macrophage migration inhibitory factor: a proven immunomodulatory cytokine? J Biol Chem 281: 29641-29651

Leng L, Chen L, Fan J, Greven D, Arjona A, Du X, Austin D, Kashgarian M, Yin Z, Huang XR, Lan HY, Lolis E, Nikolic-Paterson D, Bucala R (2011) A small-molecule macrophage migration inhibitory factor antagonist protects against glomerulonephritis in lupus-prone NZB/NZW F1 and MRL/lpr mice. J Immunol 186: 527-538

Leng L, Metz CN, Fang Y, Xu J, Donnelly S, Baugh J, Delohery T, Chen Y, Mitchell RA, Bucala R (2003) MIF signal transduction initiated by binding to CD74. J Exp Med 197: 1467-1476

Li G-Q, Xie J, Lei X-Y, Zhang L (2009) Macrophage migration inhibitory factor regulates proliferation of gastric cancer cells via the PI3K/Akt pathway. World J Gastroenterol 15: 5541

Lippa MS, Strockbine LD, Le TT, Branstetter DG, Strathdee CA, Holland PM (2007) Expression of anti-apoptotic factors modulates Apo2L/TRAIL resistance in colon carcinoma cells. Apoptosis 12: 1465-1478

Lue H, Dewor M, Leng L, Bucala R, Bernhagen J (2011) Activation of the JNK signalling pathway by macrophage migration inhibitory factor (MIF) and dependence on CXCR4 and CD74. Cell Signal 23: 135-144

Lue H, Kapurniotu A, Fingerle-Rowson G, Roger T, Leng L, Thiele M, Calandra T, Bucala R, Bernhagen J (2006) Rapid and transient activation of the ERK MAPK signalling pathway by macrophage migration inhibitory factor (MIF) and dependence on JAB1/CSN5 and Src kinase activity. Cell Signal 18: 688-703

Lue H, Thiele M, Franz J, Dahl E, Speckgens S, Leng L, Fingerle-Rowson G, Bucala R, Lüscher B, Bernhagen J (2007) Macrophage migration inhibitory factor (MIF) promotes cell survival by activation of the Akt pathway and role for CSN5/JAB1 in the control of autocrine MIF activity. Oncogene 26: 5046-5059

Merk M, Baugh J, Zierow S, Leng L, Pal U, Lee SJ, Ebert AD, Mizue Y, Trent JO, Mitchell R, Nickel W, Kavathas PB, Bernhagen J, Bucala R (2009) The Golgi-associated protein p115 mediates the secretion of macrophage migration inhibitory factor. J Immunol 182: 6896-6906

Meyer-Siegler KL, Iczkowski K a, Leng L, Bucala R, Vera PL (2006) Inhibition of macrophage migration inhibitory factor or its receptor (CD74) attenuates growth and invasion of DU-145 prostate cancer cells J Immunol 177: 8730-8739

Meyer-Siegler KL, Leifheit EC, Vera PL (2004) Inhibition of macrophage migration inhibitory factor decreases proliferation and cytokine expression in bladder cancer cells. BMC Cancer 4: 34

Mitchell R a, Liao H, Chesney J, Fingerle-Rowson G, Baugh J, David J, Bucala R (2002) Macrophage migration inhibitory factor (MIF) sustains macrophage proinflammatory function by inhibiting p53: regulatory role in the innate immune response. Proc Natl Acad Sci USA 99: 345-350

Mittelbronn M, Platten M, Zeiner P, Dombrowski Y, Frank B, Zachskorn C, Harter PN, Weller M, Wischhusen J (2011) Macrophage migration inhibitory factor (MIF) expression in human malignant gliomas contributes to immune escape and tumour progression. Acta neuropathol 122: 353-365

Nemajerova A, Mena P, Fingerle-Rowson G, Moll UM, Petrenko O (2007a) Impaired DNA damage checkpoint response in MIF-deficient mice. EMBO J 26: 987-997

Nemajerova A, Moll UM, Petrenko O, Fingerle-Rowson G (2007b) Macrophage migration inhibitory factor coordinates DNA damage response with the proteasomal control of the cell cycle. Cell Cycle 6: $1030-1034$

Ogawa H, Nishihira J, Sato Y, Kondo M, Takahashi N, Oshima T, Todo S (2000) An antibody for macrophage migration inhibitory factor 
suppresses tumour growth and inhibits tumour-associated angiogenesis. Cytokine 12: 309-314

Payne AS, Cornelius L (2002) The role of chemokines in melanoma tumor growth and metastasis. J Invest Dermatol 118: 915-922

Petrenko O, Moll UM (2005) Macrophage migration inhibitory factor MIF interferes with the Rb-E2F pathway. Mol Cell 17: 225-236

Ren Y, Chan HM, Fan J, Xie Y, Chen YX, Li W, Jiang GP, Liu Q, Meinhardt A, Tam PKH (2006) Inhibition of tumor growth and metastasis in vitro and in vivo by targeting macrophage migration inhibitory factor in human neuroblastoma. Oncogene 25: 3501-3508

Rendon BE, Willer SS, Zundel W, Mitchell RA (2009) Mechanisms of macrophage migration inhibitory factor (MIF)-dependent tumor microenvironmental adaptation. Exp Mol Pathol 86: 180-185

Schwartz V, Lue H, Kraemer S, Korbiel J, Krohn R, Ohl K, Bucala R, Weber C, Bernhagen J (2009) A functional heteromeric MIF receptor formed by CD74 and CXCR4. FEBS Lett 583: 2749-2757

Shi X, Leng L, Wang T, Wang W, Du X, Li J, McDonald C, Chen Z, Murphy JW, Lolis E, Noble P, Knudson W, Bucala R (2006) CD44 is the signaling component of the macrophage migration inhibitory factor-CD74 receptor complex. Immunity 25: 595-606

Verjans E, Noetzel E, Bektas N, Schütz AK, Lue H, Lennartz B, Hartmann A, Dahl E, Bernhagen J (2009) Dual role of macrophage migration inhibitory factor (MIF) in human breast cancer. BMC Cancer 9: 230

Welford S, Bedogni B, Gradin K (2006) HIF1 $\alpha$ delays premature senescence through the activation of MIF. Genes Dev 20: 3366-3371

White ES, Strom SR, Wys NL, Arenberg D (2001) Non-small cell lung cancer cells induce monocytes to increase expression of angiogenic activity. J Immunol 166: 7549-7555

Wilson JM, Coletta PL, Cuthbert RJ, Scott N, MacLennan K, Hawcroft G, Leng L, Lubetsky JB, Jin KK, Lolis E, Medina F, Brieva J, Poulsom R, Markham AF, Bucala R, Hull M (2005) Macrophage migration inhibitory factor promotes intestinal tumorigenesis. Gastroenterology 129: 1485-1503

Winner M, Koong AC, Rendon BE, Zundel W, Mitchell RA (2007) Amplification of Tumor hypoxic responses by macrophage migration inhibitory factor-dependent hypoxia-inducible factor stabilization. Cancer Res 67: 186

Wu Y, Li Y-Y, Matsushima K, Baba T, Mukaida N (2008) CCL3-CCR5 axis regulates intratumoral accumulation of leukocytes and fibroblasts and promotes angiogenesis in murine lung metastasis process. J Immunol 181: 6384-6393

Zhou Q, Yan X, Gershan J, Orentas RJ, Johnson BD (2008) Expression of macrophage migration inhibitory factor by neuroblastoma leads to the inhibition of antitumor T cell reactivity in vivo. J Immunol 181: 1877-1886

This work is published under the standard license to publish agreement. After 12 months the work will become freely available and the license terms will switch to a Creative Commons Attribution-NonCommercial-Share Alike 3.0 Unported License. 